\title{
Prevention and Management of Type 2 Diabetes and Metabolic Syndrome in the Time of COVID-19: Should We Add a Cup of Coffee?
}

\author{
Sabina Semiz ${ }^{1,2 *}$ and Fadila Serdarevic ${ }^{2,3}$ \\ ${ }^{1}$ College of Medicine and Health Sciences, Khalifa University, Abu Dhabi, United Arab Emirates, ${ }^{2}$ Association South East \\ European Network for Medical Research-SOVE, Sarajevo, Bosnia and Herzegovina, ${ }^{3}$ Department of Child and Adolescent \\ Psychiatry, Erasmus Medical Centre Rotterdam, Rotterdam, Netherlands
}

OPEN ACCESS

Edited by:

Giuseppe Grosso,

NNEdPro Global Centre for Nutrition and Health, United Kingdom

Reviewed by:

Agnieszka Micek,

Jagiellonian University, Poland

Cristian Ricci,

University Hospital Leipzig, Germany

*Correspondence:

Sabina Semiz

sabina.semiz@ku.ac.ae;

sabinasemiz@hotmail.com

Specialty section:

This article was submitted to

Nutritional Epidemiology,

a section of the journal

Frontiers in Nutrition

Received: 09 July 2020

Accepted: 07 September 2020

Published: 06 October 2020

Citation:

Semiz S and Serdarevic F (2020) Prevention and Management of Type 2 Diabetes and Metabolic Syndrome in the Time of COVID-19: Should We

Add a Cup of Coffee?

Front. Nutr. 7:581680.

doi: 10.3389/fnut.2020.581680
Recent evidence shows that COVID-19 patients with existing metabolic disorders, such as diabetes and metabolic syndrome, are exposed to a high risk of morbidity and mortality. At the same time, in order to manage the pandemic, the health authorities around the world are advising people to stay at home. This results in decreased physical activity and an increased consumption of an unhealthy diet, which often leads to an increase in body weight, risk for diabetes, insulin resistance, and metabolic syndrome, and thus, paradoxically, to a high risk of morbidity and mortality due to COVID-19 complications. Here we summarize the evidence demonstrating that the promotion of a healthy life style, including physical activity and a dietary intake of natural polyphenols present in coffee and tea, has the potential to improve the prevention and management of insulin resistance and diabetes in the time of COVID-19 pandemic. Particularly, it would be pertinent to evaluate further the potential positive effects of coffee beverages, rich in natural polyphenols, as an adjuvant therapy for COVID-19, which appear not to be studied sufficiently.

Keywords: polyphenols, coffee, COVID-19, ACE2, type 2 diabetes, obesity, insulin resistance, physical activity

\section{INTRODUCTION}

As we have just approached the 10 millionth case of the novel coronavirus disease (COVID19) worldwide, an increasing amount of evidence has been accumulating to indicate its poorer prognosis in patients with diabetes and hypertension, who appear to be exposed to the greater risk of the severe morbidity and mortality (1-3). A recent meta-analysis demonstrated that the incidences of diabetes and hypertension were about two-fold higher, and cardio- and cerebrovascular diseases were three-fold higher in severe/intensive care unit (ICU) cases as compared to non-ICU severe cases (4). Similarly, another recent report showed that the triglyceride and glucose index (TyG) was associated with an increased risk of morbidity and mortality in COVID-19 patients, suggesting that this marker of insulin resistance could also be a valuable marker for identifying a poor outcome of coronavirus infection (5).

Human pathogenic coronaviruses, including severe acute respiratory syndrome coronavirus [SARSCoV] and SARSCoV-2, enter cells upon binding through angiotensin-converting enzyme 2 (ACE2), a recently characterized monocarboxypeptidase and the first ACE homolog. The ACE-2 receptor is a part of the renin-angiotensin-system (RAS), consisting of classical ACE-Ang-II-AT1R axis and non-classical, recently discovered ACE-2-(A1-7)-Mas axis. The enzyme ACE2 generates 
additional RAS peptides, such as Angiotensin-1-7 (A1-7), which is associated with the unique functions of this multifaceted system (6). Interestingly, an upregulation of ACE-Ang-II-AT1R axis leading to pro-inflammatory effects, insulin secretory defects and increased insulin resistance was demonstrated in people with underlying lipid and other metabolic disturbances, such as in the case of metabolic syndrome and diabetes (2). In parallel, there is a downregulation of ACE-2-(A1-7)-Mas axis and thus, diminished anti-inflammatory effects and protection against pancreatitis and insulin resistance. It is proposed that the already distraught ACE-2-(A1-7)-Mas in diabetes/insulin resistance is additionally strained due to the virus's use of the ACE-2 to enter the host cell (2).

ACE2 is expressed in the lung, intestine, kidney, blood vessels, cardiomyocytes, immune and other cells (7-12). Since ACE2 is expressed in the liver (13), skeletal muscle (14), and adipose tissue (15), it is proposed that by being present in these insulin sensitive organs, the ACE2 may have a role in regulating insulin sensitivity and glucose homeostasis (16). ACE2 expression is reduced in patients with Type 2 Diabetes (T2D) and kidney dysfunction $(17,18)$. It was also suggested that decreased expression of ACE2 and use of RAS system antagonists in diabetes management may contribute to poor prognosis in COVID-19 patients (19). Furthermore, ACE2 genetic variants are reported to be associated with T2D, hypertension, dyslipidemia, carotid arteriosclerosis and left ventricular remodeling (20). It was suggested that ACE2 polymorphisms may be used as novel risk markers for the left ventricular hypertrophy (LVH) in hypertensive patients (21) and ACE2 variation was indicated to be associated with risk for cardiomyopathies (22). Indeed, recent COVID-19 cases demonstrated cardiac dysfunction as a serious complication and prognostic tool (23).

Previous studies have shown that ACE2 knockout mice had impaired glucose tolerance or diabetes, as well as dysfunction of endoplasmic reticulum and mitochondria in skeletal muscle that could be improved by ACE2 activation (24). Interestingly, Takeda et al. (16) demonstrated a beneficial role of ACE2 in T2D management and a protective role against caloric overload, likely via regulation of GLUT4 expression and glucose uptake (16). It was also shown that the activation of the ACE2/(A1-7)/Mas axis can improve hepatic insulin resistance, increase glucose uptake and decrease glycogen synthesis in the liver (25), therefore ACE2 was suggested to be a novel drug target for treating insulin resistance (26).

ACE2 enzyme has been also identified in pancreatic islets and it was recommended to monitor serious COVID-19 cases for the pancreas damage (27). A protective role of ACE2 in the pancreas was suggested based on the recent findings of an increased ratio of dedifferentiated beta cells in ACE2-knockout mice under high-fat diet and consequent insulin resistance, which was improved after the administration of A1-7 (28). A recent review outlined several protective effects of the A17 mimetics observed in animal studies, including protection from atherogenesis, cardiovascular dysfunction, and cardiac hypertrophy (29). It was shown that high glucose levels can activate the ACE2/(A1-7)/Mas and APN/Ang IV/IRAP RAS axes simultaneously with increased insulin secretion in the rat insulinoma cell line (30). Frantz et al. (31) demonstrated that enalapril treatment protected against the body mass increase, normalized the islet morphology, function, and beta cell mass, thus preserving the pancreatic beta-cell function probably by activating the $\mathrm{ACE} 2 /(\mathrm{A} 1-7) / \mathrm{Mas}$ receptor axis.

\section{PHYSICAL ACTIVITY AND COVID-19}

Due to the COVID-19 pandemic, a large number of people around the world have been in self-isolation or quarantine for several weeks or months. In addition, social activities have been discouraged, unhealthy diets are being consumed in higher amounts, while exercise facilities, national parks, and playgrounds have been closed. A recent study examined adults' physical activity during the COVID-19 imposed confinement in Belgium, and found that most of the people participating in the study reported to exercise less and sit more during the lockdown (32). Another study performed in the USA showed that $48 \%$ of obese patients exercised less, 50\% increased food stockpiling and about $60 \%$ increased stress-related eating, while $73 \%$ of them reported increased anxiety and $84 \%$ augmented depression since the confinement was initiated (33). A recent USA survey indicated that about $90 \%$ of responders spent more time at home and $22 \%$ gained 5-10 pounds, mostly due to absence of dietary restraint, stress-stimulated eating, and reduced physical activity imposed by COVID-19 confinement (34). Furthermore, an Italian survey performed in April 2020 indicated that weight gain was observed in almost $50 \%$ of the population, despite some positive self-implemented life style modifications (35). A recent international online survey, performed in Asian, African and European populations, reported the negative effect of COVID19 home confinement on all physical activity intensity levels, including vigorous, moderate, and walking activities, as well as showed that daily sitting time increased from 5 to $8 \mathrm{~h}$ per day, along with unhealthier food consumption and meal plan (36).

Recent studies explored the health impacts of a prolonged reduction in physical activity and overeating under circumstances of home confinement and found that increased total body fat and elevated levels of inflammatory cytokines appear to be major factors in exacerbation of insulin resistance (1). Another unhealthy consequence of COVID-19 imposed home confinement is the limited exposure to daily light, which can lead to decreased levels of Vitamin D, essential to perturb viral cellular infection by interacting with ACE2 cell entry receptors (37). In addition to the well-established association between vitamin $\mathrm{D}$ deficiency and insulin resistance and T2D risk (38), recent publications suggest its association with COVID-19 severity $(39,40)$.

\section{MANAGEMENT OF INSULIN RESISTANCE IN THE TIME OF COVID-19}

In order to combat the undesirable changes in the lifestyle and dietary habits adopted during the current COVID-19 pandemic, personalized lifestyle modifications, including home exercising and consuming healthy food, are being promoted. A recent study 
recommended regular exercise, together with a modest (20-25\%) reduction in caloric intake, for protecting cardiovascular function (41) and inducing positive immunomodulatory effects (42). Furthermore, exercise-induced immunomodulation might be a key tool in improving immune responses against the SARS-CoV2 infection. This is in line with the well-established intervention to increase physical activity and reduce body weight as the first-line recommendation in preventing and treating insulin resistance, (pre)diabetes, metabolic syndrome, and other related disorders (43), which apparently has a high potential to diminish risk of severe form of COVID-19.

In addition to stimulating healthy lifestyle choices, the management of insulin resistance, pre-diabetes and $\mathrm{T} 2 \mathrm{D}$ is supported by pharmacological treatment, with multiple targets for preventive and treatment interventions. As described earlier, the key components in SARSCoV-2 viral entry are ACE2 receptor for cell entrance and the serine protease TMPRSS2 for the proteolytic cleavage of viral spike (S) protein (44). Recently, it was shown that T2D patients had increased plasma total protease and serine protease activities (45). Interestingly, plasma serine protease activity was positively associated with levels of hemoglobin A1c (HbAlc), body mass index (BMI) and homeostasis model assessment-insulin resistance (HOMA-IR) index, thus, supporting the potential role of serine protease in development of T2D and offering novel drug targets for T2D management (45). Furthermore, it was proposed that the already available recombinant ACE2 may be employed for treating COVID-19 (46).

Evidence has been accumulating to demonstrate the beneficial effects of metformin, the first-choice oral anti-diabetic drug, in treating several other aging-related diseases, including obesity, pre-diabetes, metabolic syndrome, cardiovascular disease, nonalcoholic fatty liver disease (NAFLD), cancer, cognitive decline (47), as well as immunomodulatory, and other defects (48-50). Interestingly, a recent study performed in the Tongji Hospital of Wuhan in China showed that diabetes treatment with metformin was associated with decreased mortality as compared to diabetics not treated with this medication (51). Furthermore, it was suggested that metformin may have an inhibitory effect on the virus, through increased insulin sensitivity (52). Another study performed in the patients older than 65 years of age, who were hospitalized with pneumonia and with a history of diabetes, found that the preceding metformin treatment was associated with a markedly lower death rate in those patients (53). In line with this, it was recently suggested to use metformin as an adjuvant therapy in older, obese, and diabetic patients with COVID-19, who would benefit from this treatment through the reduction of weight, pneumonia, and protrombotic events, partially through the metformin's ability to prevent inflammation and decrease high circulating levels of cytokines, such as interleukin-6 (IL-6) (54). However, another recent paper cautioned that in patients with severe forms of COVID-19, who are exposed to the risks of lactic acidosis and ketoacidosis, metformin and sodium-glucose co-transporter-2 (SGLT2) inhibitors should be discontinued (55).

Furthermore, a recent study showed that pioglitazone treatment significantly increased the serum levels of ACE2, angiotensin-(1-7) and the hepatic ACE2 expression (56).
Pioglitazone belongs to the class of oral antidiabetic drugs, thiazolidinediones (TZD), which were introduced about 10 years ago and widely used to treat insulin resistance and T2D until recently, when discontinued due to increased cardiovascular risk associated with rosiglitazone administration (57). However, TZDs use for the treatment of other diseases has been revaluated in regards to their anti-inflammatory properties (58), including their potential use in treating COVID-19.

\section{BENEFICIAL EFFECTS OF DIETARY POLYPHENOLS IN COVID-19 MANAGEMENT}

A growing evidence from epidemiological studies demonstrated that dietary polyphenols might be used to treat and prevent T2D obesity, and insulin resistance (59). Polyphenols from the grape seed, olive oil, tea, coffee, propolis, cocoa, and chocolate have been shown to have anti-diabetic effects through reducing insulin resistance, glucose and HbAlc levels (60). Resveratrol is a polyphenol and potent antioxidant found in grape, which demonstrated anti-inflammatory and antiviral activity against several viruses (61). A recent meta-analysis indicated that resveratrol may improve cardiometabolic status and alleviate certain risk factors for cardiovascular disease, including insulin resistance and elevated cholesterol levels (62). Furthermore, previous studies demonstrated that resveratrol can deactivate the renin-angiotensin system $(63,64)$ and have a protective role by upregulating ACE2 (65). Interestingly, as the recent report suggested, resveratrol can be a promising anti-COVID-19 drug candidate, likely acting through interference with the viral spike protein function (66). This is in line with the results from previous studies, which have shown that resveratrol inhibited the Middle East Respiratory Syndrome coronavirus (MERS$\mathrm{CoV}$ ), extended cellular survival after virus infection (67), and demonstrated antiviral activity against other viruses (68).

In addition to resveratrol, other polyphenols also demonstrated a beneficial effect in COVID-19 management. Recent reports summarized diverse natural compounds, with the majority being classified as polyphenols, which demonstrated their potential to inhibit coronavirus in humans $(69,70)$, as well as other viruses (71-74). The potential effects of curcumin, a natural polyphenolic compound, include inhibition of the entry of virus, its encapsulation, and activity of viral protease, suggesting its therapeutic potential in treating SARS-CoV-2 (75). The major components of tea polyphenols, such as theaflavins, showed anti-HIV effect (76), while catechins demonstrated anti-diabetic (77) and hypocholesterolemic activities (78). Furthermore, tea extracts showed antioxidant activity (79) and beneficial effects on protein oxidation- and glycation-associated diseases (80). Importantly, the tea components also showed antiviral activity against the influenza $\mathrm{B}, \mathrm{H} 1 \mathrm{~N} 1$ and $\mathrm{H} 3 \mathrm{~N} 2$ influenza viruses, most likely through the inhibiting of virus adsorption and replication (81). It has been shown that green tea extract can be used as natural disinfectant $(82,83)$. In addition to their virucidal activity against a spectra of viruses, including influenza virus, herpes simplex virus, vaccinia virus, coxsackie virus, poliovirus-1, and human rotavirus, theaflavins also 
demonstrated the ability to alleviate bovine rotavirus and bovine coronavirus infections (84). The beneficial effects of green tea, black tea, and oolong tea have been well-known for many years and a recent study demonstrated that oolonghomobisflavan-A is a potential bioactive molecule responsible for beneficial tea effects, most likely acting through the inhibition of the main protease of SARS-CoV-2 (85). Three polyphenols, including epicatechingallate, epigallocatechin gallate, and gallocatechin3-gallate, from green tea were selected as promising drug candidates to treat COVID-19 due to their strong interaction with one or both residues in Cys145-His41 catalytic dyad of the main protease of SARS-COV-2 (86).

\section{COFFEE IN THE TIME OF COVID-19}

In addition to tea, coffee is another commonly consumed beverage in the world, which appears to increase insulin sensitivity and glucose uptake in skeletal muscle. A recent report identified for the first time that the phytochemicals from coffee and cocoa affect the phosphorylation of the insulin receptor signaling pathway and stimulated GLUT-4 translocation, increasing intracellular glucose utilization (87). In line with this, a systematic review of clinical trials analyzing the effects of coffee consumption on glucose metabolism, indicated an improvement of insulin response and glucose metabolism in long-term studies (88). Previous studies have shown that in animal models chronic caffeine intake prevented and reversed insulin resistance induced by aging and hypercaloric diets (89). Recently, coffee consumption by high-risk diabetic individuals was positively associated with pancreatic beta cell function, so they had lower fasting glucose levels, higher insulin levels and higher insulin secretion indexes upon coffee intake (90). Furthermore, a recent systematic review and meta-analysis showed that green coffee supplementation significantly decreased levels of fasting glucose, insulin, and triglyceride, and improved HDL levels, thus positively affecting the cardiometabolic risk factors (91). Nikpayam et al. (92) also demonstrated a similar effect of green coffee extract on fasting glucose levels and HOMAIR. Chlorogenic acid, the most abundant biologically active dietary polyphenol in coffee, has been suggested to be responsible for alleviating several cardiometabolic risk factors (93). These beneficial anti-diabetic, anti-obesity, anti-inflammatory and anti-carcinogenic effects seem to be further accompanied by immunomodulatory effects and changes in gut microbiota (94). Interestingly, derivatives of chlorogenic acid, including 3,4O-dicaffeoyl-1,5- $\gamma$-quinide, showed in vitro a potent antiviral effect against respiratory syncytial virus, probably acting on an intracellular post-entry replication step (95). Thus, these data suggest that drinking coffee may represent an additional, beneficial strategy in treating viral disease. However, based on our

\section{REFERENCES}

1. Martinez-Ferran M, de la Guia-Galipienso F, Sanchis-Gomar F, ParejaGaleano H. Metabolic impacts of confinement during the covid-19 pandemic knowledge, it appears that these studies have not been performed in vivo yet.

In line with described antidiabetic effects of tea polyphenols, a recent study performed in about 130.000 Korean adults found that increased coffee consumption (more than four cups per day) was associated with a lower prevalence of metabolic syndrome, as compared to non-coffee consumers (96). Another recent study also performed in Korean populations demonstrated that moderate to high coffee intake is inversely associated with the metabolic syndrome (97). Similarly, positive effects of coffee consumption were also demonstrated in Polish population, in which coffee intake was inversely associated with a risk of metabolic syndrome (98-100) and T2D (101). Furthermore, recent studies performed in Japan and Brazil, showed that decaffeinated coffee consumption improved insulin sensitivity in healthy men $(102,103)$. Another study from Sweden showed an advantage of filtered over boiled coffee when it comes to the protective role of coffee on T2D development (104). It was suggested that long-term consumption of coffee beverages is associated with a lower risk of T2D, probably via multiple mechanisms, including effects on glucose homeostasis, oxidative stress and inflammation (105). Therefore, it would be pertinent to study the potential effects of coffee intake in management and prevention of viral disease, including COVID-19, which seem not be studied in vivo yet. At the same time, it would also be important to evaluate further the potential detrimental effects of coffee intake, for example, its effects on sleep quality (106) and endothelial vascular function $(107,108)$, which may also affect COVID-19 outcome.

\section{CONCLUSION}

Thus, apart from existing general preventive and safety measures recommended to the general public, maintaining physical activity and choosing a diet and beverages rich in polyphenols, such as tea and coffee, might be important interventions in achieving an optimal public health and offering more efficient and enjoyable way to deal with the COVID-19 pandemic. Particularly, the potential positive effects of coffee consumption as an adjuvant therapy for preventing and managing COVID-19 seem not to be elucidated enough, so further studies are warranted to confirm these beneficial properties.

\section{AUTHOR CONTRIBUTIONS}

SS conceptualized the topic, researched and analyzed the literature, and wrote the manuscript, including interpretations. FS analyzed background literature and contributed to the conception of the topic, manuscript draft and interpretation, and revised the manuscript critically for its intellectual content. All authors approved the final version of the manuscript.

due to modified diet and physical activity habits. Nutrients. (2020) 12:1549. doi: 10.3390/nu12061549

2. Dalan R, Bornstein SR, El-Armouche A, Rodionov RN, Markov A, Wielockx B, et al. The ACE-2 in COVID-19: foe or 
friend? Horm Metab Res. (2020) 52:257-63. doi: 10.1055/a-115 5-0501

3. Zbinden-Foncea H, Francaux M, Deldicque L, Hawley JA. Does high cardiorespiratory fitness confer some protection against pro-inflammatory responses after infection by SARS-CoV-2? Obesity. (2020) 28:1378-81. doi: 10.1002/oby.22849

4. Li B, Yang J, Zhao F, Zhi L, Wang X, Liu L, et al. Prevalence and impact of cardiovascular metabolic diseases on COVID-19 in China. Clin Res Cardiol. (2020) 109:531-8. doi: 10.1007/s00392-020-01626-9

5. Ren H, Yang Y, Wang F, Yan Y, Shi X, Dong K, et al. Association of the insulin resistance marker TyG index with the severity and mortality of COVID-19. Cardiovasc Diabetol. (2020) 19:58. doi: 10.1186/s12933-020-01035-2

6. Pahlavani M, Kalupahana NS, Ramalingam L, Moustaid-Moussa $\mathrm{N}$. Regulation and functions of the renin-angiotensin system in white and brown adipose tissue. Compr Physiol. (2017) 7:1137-50. doi: 10.1002/cphy.c160031

7. Kuba K, Imai Y, Rao S, Gao H, Guo F, Guan B, et al. A crucial role of angiotensin converting enzyme 2 (ACE2) in SARS coronavirus-induced lung injury. Nat Med. (2005) 11:875-9. doi: 10.1038/nm1267

8. Guo Y, Korteweg C, McNutt MA, Gu J. Pathogenetic mechanisms of severe acute respiratory syndrome. Virus Res. (2008) 133:4-12. doi: 10.1016/j.virusres.2007.01.022

9. Lukassen S, Chua RL, Trefzer T, Kahn NC, Schneider MA, Muley $\mathrm{T}$, et al. SARS-CoV-2 receptor ACE2 and TMPRSS2 are primarily expressed in bronchial transient secretory cells. EMBO J. (2020) 39:e105114. doi: 10.15252/embj.20105114

10. Magrone T, Magrone M, Jirillo E. Focus on receptors for coronaviruses with special reference to angiotensin-converting enzyme 2 as a potential drug target-a perspective. Endocr Metab Immune Disord Drug Targets. (2020) 20:807-11. doi: 10.2174/1871530320666200427112902

11. Tipnis SR, Hooper NM, Hyde R, Karran E, Christie G, Turner AJ. A human homolog of angiotensin-converting enzyme. Cloning and functional expression as a captopril-insensitive carboxypeptidase. J Biol Chem. (2000) 275:33238-43. doi: 10.1074/jbc.M002615200

12. Santos RA. Angiotensin-(1-7). Hypertension. (2014) 63:113847. doi: 10.1161/HYPERTENSIONAHA.113.01274

13. Paizis G, Tikellis C, Cooper ME, Schembri JM, Lew RA, Smith $\mathrm{AI}$, et al. Chronic liver injury in rats and humans upregulates the novel enzyme angiotensin converting enzyme 2. Gut. (2005) 54:17906. doi: $10.1136 /$ gut. 2004.062398

14. Fernandes T, Hashimoto NY, Oliveira EM. Characterization of angiotensinconverting enzymes 1 and 2 in the soleus and plantaris muscles of rats. Braz J Med Biol Res. (2010) 43:837-42. doi: 10.1590/S0100-879X2010007500088

15. Gupte M, Boustany-Kari CM, Bharadwaj K, Police S, Thatcher S, Gong MC, et al. ACE2 is expressed in mouse adipocytes and regulated by a high-fat diet. Am J Physiol Regul Integr Comp Physiol. (2008) 295:R7818. doi: 10.1152/ajpregu.00183.2008

16. Takeda M, Yamamoto K, Takemura Y, Takeshita H, Hongyo K, Kawai $\mathrm{T}$, et al. Loss of ACE2 exaggerates high-calorie diet-induced insulin resistance by reduction of GLUT4 in mice. Diabetes. (2013) 62:22333. doi: $10.2337 / \mathrm{db} 12-0177$

17. Reich HN, Oudit GY, Penninger JM, Scholey JW, Herzenberg AM. Decreased glomerular and tubular expression of ACE2 in patients with type 2 diabetes and kidney disease. Kidney Int. (2008) 74:1610-6. doi: 10.1038/ki.2008.497

18. Mizuiri S, Hemmi H, Arita M, Ohashi Y, Tanaka Y, Miyagi M, et al. Expression of ACE and ACE2 in individuals with diabetic kidney disease and healthy controls. Am J Kidney Dis. (2008) 51:61323. doi: 10.1053/j.ajkd.2007.11.022

19. Pal R, Bhadada SK. COVID-19 and diabetes mellitus: an unholy interaction of two pandemics. Diabetes Metab Syndr. (2020) 14:5137. doi: $10.1016 /$ j.dsx.2020.04.049

20. Liu C, Li Y, Guan T, Lai Y, Shen Y, Zeyaweiding A, et al. ACE2 polymorphisms associated with cardiovascular risk in Uygurs with type 2 diabetes mellitus. Cardiovasc Diabetol. (2018) 17:127. doi: 10.1186/s12933-0180771-3

21. Fan Z, Wu G, Yue M, Ye J, Chen Y, Xu B, et al. Hypertension and hypertensive left ventricular hypertrophy are associated with ACE2 genetic polymorphism. Life Sci. (2019) 225:39-45. doi: 10.1016/j.lfs.2019.03.059
22. Kumar A, Rani B, Sharma R, Kaur G, Prasad R, Bahl A, et al. ACE2, CALM3 and TNNI3K polymorphisms as potential disease modifiers in hypertrophic and dilated cardiomyopathies. Mol Cell Biochem. (2018) 438:167-74. doi: 10.1007/s11010-017-3123-9

23. Kishor K, Marwah R, Anantharaj A, Kalra S. Cardiovigilance in COVID 19. J Pak Med Assoc. (2020) 70(Suppl. 3):S77-80. doi: 10.5455/JPMA.14

24. Cao X, Lu XM, Tuo X, Liu JY, Zhang YC, Song LN, et al. Angiotensinconverting enzyme 2 regulates endoplasmic reticulum stress and mitochondrial function to preserve skeletal muscle lipid metabolism. Lipids Health Dis. (2019) 18:207. doi: 10.1186/s12944-019-1145-x

25. Cao X, Yang FY, Xin Z, Xie RR, Yang JK. The ACE2/Ang-(1-7)/Mas axis can inhibit hepatic insulin resistance. Mol Cell Endocrinol. (2014) 393:308. doi: 10.1016/j.mce.2014.05.024

26. Zhong JC, Yu XY, Lin QX, Li XH, Huang XZ, Xiao DZ, et al. Enhanced angiotensin converting enzyme 2 regulates the insulin/Akt signalling pathway by blockade of macrophage migration inhibitory factor expression. Br J Pharmacol. (2008) 153:66-74. doi: 10.1038/sj.bjp.0707482

27. Liu F, Long X, Zhang B, Zhang W, Chen X, Zhang Z. ACE2 expression in pancreas may cause pancreatic damage after SARS-CoV-2 infection. Clin Gastroenterol Hepatol. (2020) 18:2128-30.e2. doi: 10.1016/j.cgh.2020. 04.040

28. Xuan X, Gao F, Ma X, Huang C, Wang $Y$, Deng $H$, et al. Activation of ACE2/angiotensin (1-7) attenuates pancreatic beta cell dedifferentiation in a high-fat-diet mouse model. Metabolism. (2018) 81:83-96. doi: 10.1016/j.metabol.2017.12.003

29. Li XC, Zhang J, Zhuo JL. The vasoprotective axes of the reninangiotensin system: physiological relevance and therapeutic implications in cardiovascular, hypertensive and kidney diseases. Pharmacol Res. (2017) 125(Pt A):21-38. doi: 10.1016/j.phrs.2017.06.005

30. Hardtner C, Morke C, Walther R, Wolke C, Lendeckel U. High glucose activates the alternative ACE2/Ang-(1-7)/Mas and APN/Ang IV/IRAP RAS axes in pancreatic beta-cells. Int J Mol Med. (2013) 32:795804. doi: 10.3892/ijmm.2013.1469

31. Frantz ED, Crespo-Mascarenhas C, Barreto-Vianna AR, Aguila MB, Mandarim-de-Lacerda CA. Renin-angiotensin system blockers protect pancreatic islets against diet-induced obesity and insulin resistance in mice. PLoS ONE. (2013) 8:e67192. doi: 10.1371/journal.pone.0067192

32. Constandt B, Thibaut E, De Bosscher V, Scheerder J, Ricour M, Willem A. Exercising in Times of lockdown: an analysis of the impact of COVID-19 on levels and patterns of exercise among adults in Belgium. Int J Environ Res Public Health. (2020) 17:4144. doi: 10.3390/ijerph17114144

33. Almandoz JP, Xie L, Schellinger JN, Mathew MS, Gazda C, Ofori $\mathrm{A}$, et al. Impact of COVID-19 stay-at-home orders on weightrelated behaviors among patients with obesity. Clin Obes. (2020) 10:e12386. doi: 10.1111/cob.12386

34. Zachary Z, Brianna F, Brianna L, Garrett P, Jade W, Alyssa $D$, et al. Self-quarantine and weight gain related risk factors during the COVID-19 pandemic. Obes Res Clin Pract. (2020) 14:210-6. doi: 10.1016/j.orcp.2020.05.004

35. Di Renzo L, Gualtieri P, Pivari F, Soldati L, Attina A, Cinelli G, et al. Eating habits and lifestyle changes during COVID-19 lockdown: an Italian survey. $J$ Transl Med. (2020) 18:229. doi: 10.1186/s12967-020-02399-5

36. Ammar A, Brach M, Trabelsi K, Chtourou H, Boukhris O, Masmoudi L, et al. Effects of COVID-19 home confinement on eating behaviour and physical activity: results of the ECLB-COVID19 international online survey. Nutrients. (2020) 12:1583. doi: 10.3390/nu12061583

37. Iddir M, Brito A, Dingeo G, Fernandez Del Campo SS, Samouda H, La Frano MR, et al. Strengthening the immune system and reducing inflammation and oxidative stress through diet and nutrition: considerations during the COVID-19 crisis. Nutrients. (2020) 12:1562. doi: 10.3390/nu1206 1562

38. Pittas AG, Lau J, Hu FB, Dawson-Hughes B. The role of vitamin D and calcium in type 2 diabetes. A systematic review and meta-analysis. J Clin Endocrinol Metab. (2007) 92:2017-29. doi: 10.1210/jc.2007-0298

39. Rhodes JM, Subramanian S, Laird E, Kenny RA. Editorial: low population mortality from COVID-19 in countries south of latitude 35 degrees North supports vitamin $\mathrm{D}$ as a factor determining severity. Aliment Pharmacol Ther. (2020) 51:1434-7. doi: 10.1111/apt.15777 
40. Ali N. Role of vitamin D in preventing of COVID-19 infection, progression and severity. J Infect Public Health. (2020) S1876-0341:305311. doi: 10.1016/j.jiph.2020.06.021

41. Narici M, De Vito G, Franchi M, Paoli A, Moro T, Marcolin G, et al. Impact of sedentarism due to the COVID-19 home confinement on neuromuscular, cardiovascular and metabolic health: physiological and pathophysiological implications and recommendations for physical and nutritional countermeasures. Eur J Sport Sci. (2020). doi: 10.1080/17461391.2020.1761076. [Epub ahead of print].

42. Leandro CG, Ferreira ESWT, Lima-Silva AE. Covid-19 and exerciseinduced immunomodulation. Neuroimmunomodulation. (2020) 27:758. doi: $10.1159 / 000508951$

43. Nilsson PM, Tuomilehto J, Ryden L. The metabolic syndrome-what is it and how should it be managed? Eur J Prev Cardiol. (2019) 26(Suppl. 2):33-46. doi: 10.1177/2047487319886404

44. Hoffmann M, Kleine-Weber H, Schroeder S, Kruger N, Herrler T, Erichsen $S$, et al. SARS-CoV-2 cell entry depends on ACE2 and TMPRSS2 and is blocked by a clinically proven protease inhibitor. Cell. (2020) 181:27180.e8. doi: $10.1016 /$ j.cell.2020.02.052

45. Kuo CS, Chen JS, Lin LY, Schmid-Schonbein GW, Chien S, Huang $\mathrm{PH}$, et al. Inhibition of serine protease activity protects against high fat diet-induced inflammation and insulin resistance. Sci Rep. (2020) 10:1725. doi: 10.1038/s41598-020-58361-4

46. Batlle D, Wysocki J, Satchell K. Soluble angiotensin-converting enzyme 2: a potential approach for coronavirus infection therapy? Clin Sci. (2020) 134:543-5. doi: $10.1042 / C S 20200163$

47. Zhou J, Massey S, Story D, Li L. Metformin: an old drug with new applications. Int J Mol Sci. (2018) 19:2863. doi: 10.3390/ijms19102863

48. Pollak M. The effects of metformin on gut microbiota and the immune system as research frontiers. Diabetologia. (2017) 60:16627. doi: $10.1007 / \mathrm{s} 00125-017-4352-\mathrm{x}$

49. Tomczynska M, Bijak M, Saluk J. Metformin-the drug for the treatment of autoimmune diseases; a new use of a known anti-diabetic drug. Curr Top Med Chem. (2016) 16:2223-30. doi: 10.2174/1568026616666160216152324

50. Ursini F, Russo E, Pellino G, D'Angelo S, Chiaravalloti A, De Sarro G, et al. Metformin and autoimmunity: a "new deal" of an old drug. Front Immunol. (2018) 9:1236. doi: 10.3389/fimmu.2018.01236

51. Luo P, Qiu L, Liu Y, Liu XL, Zheng JL, Xue HY, et al. Metformin treatment was associated with decreased mortality in COVID-19 patients with diabetes in a retrospective analysis. Am J Trop Med Hyg. (2020) 103:69-72. doi: 10.4269/ajtmh.20-0375

52. Chen Y, Gu F, Guan JL. Metformin might inhibit virus through increasing insulin sensitivity. Chin Med J. (2018) 131:376-7. doi: 10.4103/0366-6999.223856

53. Mortensen E, Anzueto A. Association of metformin and mortality for patients with diabetes who are hospitalized with pneumonia. Eur Respir J. (2018) 52:PA2639. doi: 10.1183/13993003.congress-2018

54. Menendez JA. Metformin and SARS-CoV-2: mechanistic lessons on air pollution to weather the cytokine/thrombotic storm in COVID-19. Aging. (2020) 12:8760-5. doi: 10.18632/aging.103347

55. Orioli L, Hermans MP, Thissen JP, Maiter D, Vandeleene B, Yombi JC. COVID-19 in diabetic patients: related risks and specifics of management. Ann Endocrinol. (2020) 81:101-9. doi: 10.1016/j.ando.2020. 05.001

56. Zhang W, Li C, Liu B, Wu R, Zou N, Xu YZ, et al. Pioglitazone upregulates hepatic angiotensin converting enzyme 2 expression in rats with steatohepatitis. Ann Hepatol. (2013) 12:892-900. doi: 10.1016/S1665-2681(19)31294-3

57. Wallach JD, Wang K, Zhang AD, Cheng D, Grossetta Nardini HK, Lin H, et al. Updating insights into rosiglitazone and cardiovascular risk through shared data: individual patient and summary level meta-analyses. BMJ. (2020) 368:17078. doi: 10.1136/bmj.17078

58. Carboni E, Carta AR, Carboni E. Can pioglitazone be potentially useful therapeutically in treating patients with COVID-19? Med Hypotheses. (2020) 140:109776. doi: 10.1016/j.mehy.2020.109776

59. Cory H, Passarelli S, Szeto J, Tamez M, Mattei J. The role of polyphenols in human health and food systems: a mini-review. Front Nutr. (2018) 5:87. doi: 10.3389/fnut.2018.00087
60. Cao H, Ou J, Chen L, Zhang Y, Szkudelski T, Delmas D, et al. Dietary polyphenols and type 2 diabetes: human study and clinical trial. Crit Rev Food Sci Nutr. (2019) 59:3371-9. doi: 10.1080/10408398.2018.14 92900

61. Marinella MA. Indomethacin and resveratrol as potential treatment adjuncts for SARS-CoV-2/COVID-19. Int J Clin Pract. (2020) 74:e13535. doi: 10.1111/ijcp.13535

62. Sergi C, Chiu B, Feulefack J, Shen F, Chiu B. Usefulness of resveratrol supplementation in decreasing cardiometabolic risk factors comparing subjects with metabolic syndrome and healthy subjects with or without obesity: meta-analysis using multinational, randomised, controlled trials. Arch Med Sci Atheroscler Dis. (2020) 5:e98-111. doi: 10.5114/amsad.2020.95884

63. Tiao MM, Lin YJ, Yu HR, Sheen JM, Lin IC, Lai YJ, et al. Resveratrol ameliorates maternal and post-weaning high-fat diet-induced nonalcoholic fatty liver disease via renin-angiotensin system. Lipids Health Dis. (2018) 17:178. doi: 10.1186/s12944-018-0824-3

64. Kim EN, Kim MY, Lim JH, Kim Y, Shin SJ, Park CW, et al. The protective effect of resveratrol on vascular aging by modulation of the renin-angiotensin system. Atherosclerosis. (2018) 270:123-31. doi: 10.1016/j.atherosclerosis.2018.01.043

65. Horne JR, Vohl MC. Biological plausibility for interactions between dietary fat, resveratrol, ACE2, and SARS-CoV illness severity. Am J Physiol Endocrinol Metab. (2020) 318:E830-3. doi: 10.1152/ajpendo.00150.2020

66. Wahedi HM, Ahmad S, Abbasi SW. Stilbene-based natural compounds as promising drug candidates against COVID-19. J Biomol Struct Dyn. (2020). doi: 10.1080/07391102.2020.1762743. [Epub ahead of print].

67. Lin SC, Ho CT, Chuo WH, Li S, Wang TT, Lin CC. Effective inhibition of MERS-CoV infection by resveratrol. BMC Infect Dis. (2017) 17:144. doi: 10.1186/s12879-017-2253-8

68. Xu J, Yin Z, Li L, Cheng A, Jia R, Song X, et al. Inhibitory effect of resveratrol against duck enteritis virus in vitro. PLoS ONE. (2013) 8:e65213. doi: 10.1371/journal.pone.0065213

69. Mani JS, Johnson JB, Steel JC, Broszczak DA, Neilsen PM, Walsh KB, et al. Natural product-derived phytochemicals as potential agents against coronaviruses: a review. Virus Res. (2020) 284:197989. doi: 10.1016/j.virusres.2020.197989

70. Park JY, Yuk HJ, Ryu HW, Lim SH, Kim KS, Park KH, et al. Evaluation of polyphenols from Broussonetia papyrifera as coronavirus protease inhibitors. J Enzyme Inhib Med Chem. (2017) 32:504-15. doi: 10.1080/14756366.2016.1265519

71. Chen C, Zuckerman DM, Brantley S, Sharpe M, Childress K, Hoiczyk E, et al. Sambucus nigra extracts inhibit infectious bronchitis virus at an early point during replication. BMC Vet Res. (2014) 10:24. doi: 10.1186/1746-6148-10-24

72. Yook HS, Kim KH, Park JE, Shin HJ. Antioxidative and antiviral properties of flowering cherry fruits (Prunus serrulata L. var. spontanea). Am J Chin Med. (2010) 38:937-48. doi: 10.1142/S0192415X10008366

73. Li H, Wu J, Zhang Z, Ma Y, Liao F, Zhang Y, et al. Forsythoside a inhibits the avian infectious bronchitis virus in cell culture. Phytother Res. (2011) 25:338-42. doi: 10.1002/ptr.3260

74. Sundararajan A, Ganapathy R, Huan L, Dunlap JR, Webby RJ, Kotwal $\mathrm{GJ}$, et al. Influenza virus variation in susceptibility to inactivation by pomegranate polyphenols is determined by envelope glycoproteins. Antiviral Res. (2010) 88:1-9. doi: 10.1016/j.antiviral.2010.06.014

75. Zahedipour F, Hosseini SA, Sathyapalan T, Majeed M, Jamialahmadi T, AlRasadi K, et al. Potential effects of curcumin in the treatment of COVID-19 infection. Phytother Res. (2020). doi: 10.1002/ptr.6738. [Epub ahead of print].

76. Yang J, Li L, Tan S, Jin H, Qiu J, Mao Q, et al. A natural theaflavins preparation inhibits HIV-1 infection by targeting the entry step: potential applications for preventing HIV-1 infection. Fitoterapia. (2012) 83:34855. doi: 10.1016/j.fitote.2011.11.016

77. Murase T, Nagasawa A, Suzuki J, Hase T, Tokimitsu I. Beneficial effects of tea catechins on diet-induced obesity: stimulation of lipid catabolism in the liver. Int J Obes Relat Metab Disord. (2002) 26:1459-64. doi: 10.1038/sj.ijo.0802141

78. Ikeda I, Imasato $Y$, Sasaki E, Nakayama $M$, Nagao $H$, Takeo $T$, et al. Tea catechins decrease micellar solubility and intestinal absorption of cholesterol in rats. Biochim Biophys Acta. (1992) 1127:141-6. doi: 10.1016/0005-2760(92)90269-2 
79. Saito ST, Gosmann G, Saffi J, Presser M, Richter MF, Bergold AM. Characterization of the constituents and antioxidant activity of Brazilian green tea (Camellia sinensis var. assamica IAC-259 cultivar) extracts. J Agric Food Chem. (2007) 55:9409-14. doi: 10.1021/jf071796p

80. Nakagawa T, Yokozawa T, Terasawa K, Shu S, Juneja LR. Protective activity of green tea against free radical- and glucose-mediated protein damage. J Agric Food Chem. (2002) 50:2418-22. doi: 10.1021/jf011339n

81. Nagai E, Iwai M, Koketsu R, Okuno Y, Suzuki Y, Morimoto R, et al. Antiinfluenza virus activity of adlay tea components. Plant Foods Hum Nutr. (2019) 74:538-43. doi: 10.1007/s11130-019-00773-3

82. Shin WJ, Kim YK, Lee KH, Seong BL. Evaluation of the antiviral activity of a green tea solution as a hand-wash disinfectant. Biosci Biotechnol Biochem. (2012) 76:581-4. doi: 10.1271/bbb.110764

83. Randazzo W, Falco I, Aznar R, Sanchez G. Effect of green tea extract on enteric viruses and its application as natural sanitizer. Food Microbiol. (2017) 66:150-6. doi: 10.1016/j.fm.2017.04.018

84. Clark KJ, Grant PG, Sarr AB, Belakere JR, Swaggerty CL, Phillips TD, et al. An in vitro study of theaflavins extracted from black tea to neutralize bovine rotavirus and bovine coronavirus infections. Vet Microbiol. (1998) 63:147-57. doi: 10.1016/S0378-1135(98)00242-9

85. Bhardwaj VK, Singh R, Sharma J, Rajendran V, Purohit R, Kumar S. Identification of bioactive molecules from tea plant as SARSCoV-2 main protease inhibitors. J Biomol Struct Dyn. (2020). doi: 10.1080/07391102.2020.1766572. [Epub ahead of print].

86. Ghosh R, Chakraborty A, Biswas A, Chowdhuri S. Evaluation of green tea polyphenols as novel corona virus (SARS CoV-2) main protease (Mpro) inhibitors-an in silico docking and molecular dynamics simulation study. J Biomol Struct Dyn. (2020). doi: 10.1080/07391102.2020.1779818. [Epub ahead of print]

87. Rebollo-Hernanz M, Zhang Q, Aguilera Y, Martin-Cabrejas MA, Gonzalez de Mejia E. Relationship of the phytochemicals from coffee and cocoa byproducts with their potential to modulate biomarkers of metabolic syndrome in vitro. Antioxidants. (2019) 8:279. doi: 10.3390/antiox8080279

88. Reis CEG, Dorea JG, da Costa THM. Effects of coffee consumption on glucose metabolism: a systematic review of clinical trials. J Tradit Complement Med. (2019) 9:184-91. doi: 10.1016/j.jtcme.2018.01.001

89. Sacramento JF, Martins FO, Rodrigues T, Matafome P, Ribeiro MJ, Olea E, et al. A 2 adenosine receptors mediate whole-body insulin sensitivity in a prediabetes animal Model: primary effects on skeletal muscle. Front Endocrinol. (2020) 11:262. doi: 10.3389/fendo.2020.00262

90. Gao F, Zhang Y, Ge S, Lu H, Chen R, Fang P, et al. Coffee consumption is positively related to insulin secretion in the Shanghai high-risk diabetic screen (SHiDS) study. Nutr Metab. (2018) 15:84. doi: 10.1186/s12986-018-0321-8

91. Morvaridi M, Rayyani E, Jaafari M, Khiabani A, Rahimlou M. The effect of green coffee extract supplementation on cardio metabolic risk factors: a systematic review and meta-analysis of randomized controlled trials. J Diabetes Metab Disord. (2020) 19:645-60. doi: 10.1007/s40200-02000536-x

92. Nikpayam O, Najafi M, Ghaffari S, Jafarabadi MA, Sohrab G, Roshanravan N. Effects of green coffee extract on fasting blood glucose, insulin concentration and homeostatic model assessment of insulin resistance (HOMA-IR): a systematic review and meta-analysis of interventional studies. Diabetol Metab Syndr. (2019) 11:91. doi: 10.1186/s13098-019-0489-8

93. Tajik N, Tajik M, Mack I, Enck P. The potential effects of chlorogenic acid, the main phenolic components in coffee, on health: a comprehensive review of the literature. Eur J Nutr. (2017) 56:2215-44. doi: 10.1007/s00394-017-1379-1

94. Caro-Gomez E, Sierra JA, Escobar JS, Alvarez-Quintero R, Naranjo M, Medina S, et al. Green coffee extract improves cardiometabolic parameters and modulates gut microbiota in high-fat-diet-fed ApoE(-/-) mice. Nutrients. (2019) 11:497. doi: 10.3390/nu11030497

95. Sinisi V, Stevaert A, Berti F, Forzato C, Benedetti F, Navarini L, et al. Chlorogenic compounds from coffee beans exert activity against respiratory viruses. Planta Med. (2017) 83:615-23. doi: 10.1055/s-0042-119449

96. Shin S, Lim J, Lee HW, Kim CE, Kim SA, Lee JK, et al. Association between the prevalence of metabolic syndrome and coffee consumption among Korean adults: results from the health examinees study. Appl Physiol Nutr Metab. (2019) 44:1371-8. doi: 10.1139/apnm-2018-0880

97. Kim Y, Je Y. Moderate coffee consumption is inversely associated with the metabolic syndrome in the Korean adult population. Br J Nutr. (2018) 120:1279-87. doi: 10.1017/S0007114518002635

98. Suliga E, Koziel D, Ciesla E, Rebak D, Gluszek S. Coffee consumption and the occurrence and intensity of metabolic syndrome: a cross-sectional study. Int J Food Sci Nutr. (2017) 68:507-13. doi: 10.1080/09637486.2016.1256381

99. Micek A, Grosso G, Polak M, Kozakiewicz K, Tykarski A, Puch Walczak A, et al. Association between tea and coffee consumption and prevalence of metabolic syndrome in Poland-results from the WOBASZ II study (2013-2014). Int J Food Sci Nutr. (2018) 69:35868. doi: 10.1080/09637486.2017.1362690

100. Grosso G, Stepaniak U, Micek A, Topor-Madry R, Pikhart H, Szafraniec $\mathrm{K}$, et al. Association of daily coffee and tea consumption and metabolic syndrome: results from the Polish arm of the HAPIEE study. Eur J Nutr. (2015) 54:1129-37. doi: 10.1007/s00394-014-0789-6

101. Grosso G, Stepaniak U, Micek A, Kozela M, Stefler D, Bobak M, et al. Dietary polyphenol intake and risk of type 2 diabetes in the Polish arm of the health, alcohol and psychosocial factors in Eastern Europe (HAPIEE) study. $\mathrm{Br} \mathrm{J}$ Nutr. (2017) 118:60-8. doi: 10.1017/S0007114517001805

102. Kawada T. Decaffeinated green coffee bean extract and the components of the metabolic syndrome. Br J Nutr. (2018) 120:240. doi: 10.1017/S0007114518001289

103. Reis CEG, Paiva C, Amato AA, Lofrano-Porto A, Wassell S, Bluck LJC, et al. Decaffeinated coffee improves insulin sensitivity in healthy men. Br J Nutr. (2018) 119:1029-38. doi: 10.1017/S000711451800034X

104. Shi L, Brunius C, Johansson I, Bergdahl IA, Rolandsson O, van Guelpen B, et al. Plasma metabolite biomarkers of boiled and filtered coffee intake and their association with type 2 diabetes risk. J Intern Med. (2020) 287:40521. doi: 10.1111/joim.13009

105. Rebelo I, Casal S. Coffee: a dietary intervention on type 2 diabetes? Curr Med Chem. (2017) 24:376-83. doi: 10.2174/0929867323666161003123717

106. O'Callaghan F, Muurlink O, Reid N. Effects of caffeine on sleep quality and daytime functioning. Risk Manag Healthc Policy. (2018) 11:26371. doi: 10.2147/RMHP.S156404

107. Higashi Y. Coffee and endothelial function: a coffee paradox? Nutrients. (2019) 11:2104. doi: 10.3390/nu11092104

108. Godos J, Pluchinotta FR, Marventano S, Buscemi S, Li Volti G, Galvano F, et al. Coffee components and cardiovascular risk: beneficial and detrimental effects. Int J Food Sci Nutr. (2014) 65:925-36. doi: 10.3109/09637486.2014.940287

Conflict of Interest: The authors declare that the research was conducted in the absence of any commercial or financial relationships that could be construed as a potential conflict of interest.

Copyright (c) 2020 Semiz and Serdarevic. This is an open-access article distributed under the terms of the Creative Commons Attribution License (CC BY). The use, distribution or reproduction in other forums is permitted, provided the original author(s) and the copyright owner(s) are credited and that the original publication in this journal is cited, in accordance with accepted academic practice. No use, distribution or reproduction is permitted which does not comply with these terms. 